\title{
RESPONSES OF AN ANTARCTIC SOUTHERN GIANT PETREL POPULATION TO CLIMATE CHANGE
}

\author{
http://dx.doi.org/10.4322/apa.2014.066 \\ Lucas Krüger ${ }^{1, *}$, Martin Sander ${ }^{1}$, Maria Virginia Petry ${ }^{1}$
}

${ }^{1}$ Laboratório de Ornitologia e Animais Marinhos, Universidade do Vale do Rio dos Sinos - UNISINOS, Av. Unisinos, 950, Cristo Rei, São Leopoldo, CEP 93022-00, Rio Grande do Sul, RS, Brazil

*e-mail: biokruger@gmail.com

\begin{abstract}
The comprehension of species responses to climate change is one of our present ecological challenges. This paper aims to evaluate the demographic responses of a Southern Giant Petrel population according to climate factors. We used a Multi-State Mark-Recapture method to estimate survival from breeder and non-breeder, and transition rates. Breeder survival response to Southern Oscillation Index, Antarctic Oscillation Index and temperature. Non breeder survival response to Southern Oscillation Index and temperature and Desertion rate with response to Temperature only in summer. Southern Giant Petrels are associated with warmer sea conditions. No recent decrease caused by climate factors can be expected under the scenario of warming in Antarctic Peninsula, and actual population size makes this assumption reasonable.
\end{abstract}

Keywords: Antarctic oscillation, demography, El Niño Southern oscillation

\section{Introduction}

The annual variations of the El Niño Southern Oscillation are influential over the Antarctic Circumpolar Current (ACC). Anomalies on the ACC are directly correlated with atypical variations in the seasonal cycles of sea ice caps, disrupting trends on ocean and atmospheric temperature in Antarctica by affecting the Antarctic Oscillations (Gong \& Wang, 1999; Kwok \& Comiso, 2002).

Seabirds that breed at higher latitudes are affected by these climate variations through a disruption in demography rates (Warren et al., 2009), population size (Ainley et al., 2005) and increased area of dispersion to the north of Juvenile after fledging (Sander et al., 2010). The present paper evaluates the demographic response of an Antarctic Southern Giant Petrel (SGP) population to the Southern Oscillation Index (SOI), Antarctic Oscillation Index (AOI) and temperature in the 80 s. The demography responses of Antarctic seabirds to climate are unknown for most species. Therefore the present paper contributes to the knowledge about the influence of climate under the Antarctic biota.

\section{Materials and Methods}

The study was conducted at Elephant Island, South Shetlands, precisely at Stinker Point (61 $61^{\circ} 31^{\prime \prime}$ S and $55^{\circ} 19^{\prime} 26^{\prime \prime} \mathrm{W}$ ). Adult Southern Giant Petrels (Macronectes giganteus) were banded and recovered from 1986/1987 until 1993/1994 with aluminum bands supplied by the National Center for Conservation of Wild Birds (CEMAVE, Portuguese acronym). For evaluation of survival rates of breeder and non-breeder stages we used a Multi-State MarkRecapture Model using the data collected between 1986 and 1992. Breeding seasons: 1986-87, 1987-88, 1988-1989, 1989-90; 1990-91, 1991-92. The stages breeder and non breeder were used for the analysis. We evaluated whether the responses of survival, recapture and transition probabilities were constants or time dependents through a multi-model inference with AICc classification of best models using the Mark software. We used the rates from the 64 resulting models in a forward analysis. Demography responses to climate were tested through Analysis of Covariance ANCOVA by PASW 18.0, with $\alpha=95 \%$. 


\section{Results}

The average SOI presented a greater variation along the years than the AOI, while SOI tended to be lower in summer in the last three years of the study (Figure 1). Average temperature tended to remain positive in summer (but got close to $0{ }^{\circ} \mathrm{C}$ in the last two years) and negative in winter, with a peak in the 1989 winter, when it reached $-1{ }^{\circ} \mathrm{C}$ (Figure 2).

Breeder survival (BS) and non breeder survival (NBS) tended to show decline throughout all the years, while desertion rate (DR) showed an increasing trend. Return rate (RR) was constant along the years (Figure 3). BS answered to SOI in winter and summer, AOI in summer and to temperature in winter. The greater slope was positive: AOI in summer. NBS answered only to SOI and temperature in winter, with a greater slope in winter SOI, but both values very closed. DR was only related to temperature in summer (negative slope) and RR was not related to any climate variable (Table 1, Figure 3).

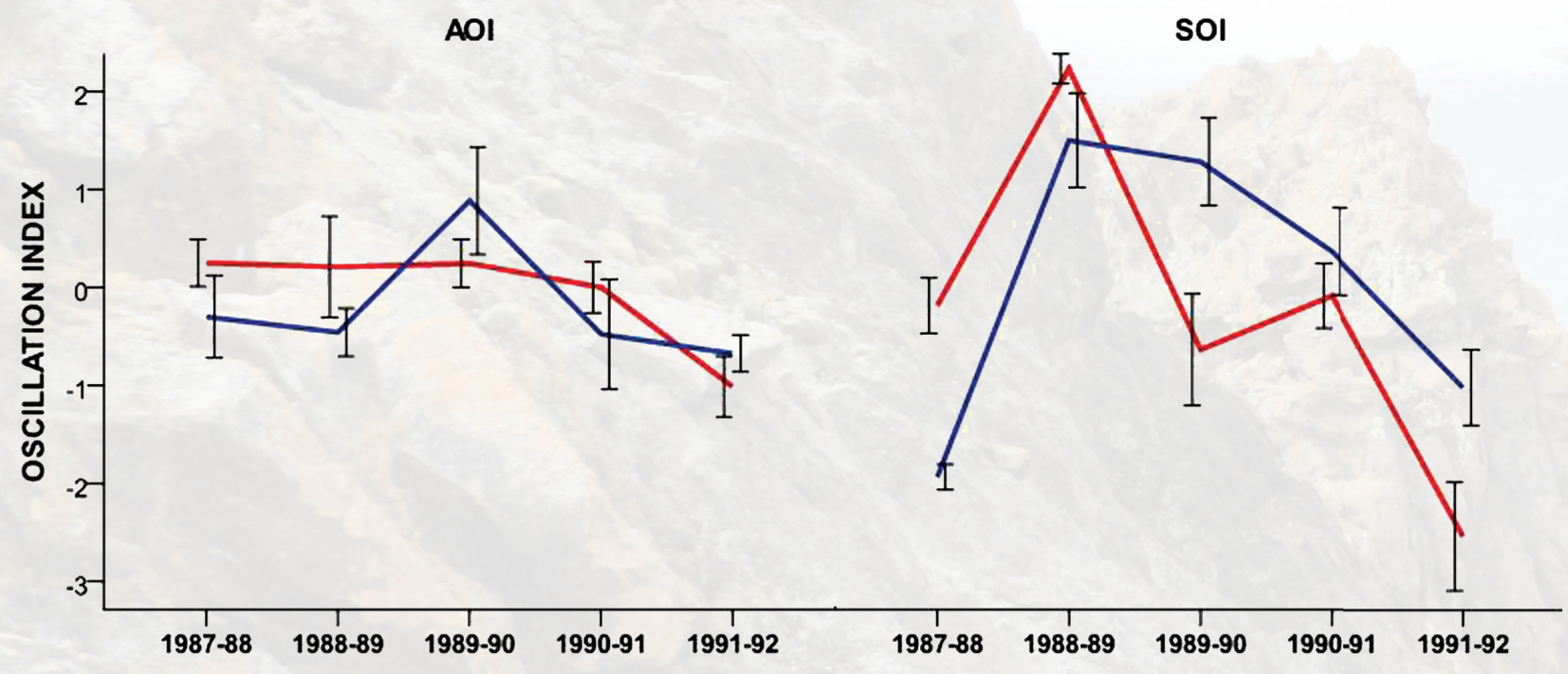

Figure 1. Year average Antarctic Oscillation Index AOI (left) and Southern Oscillation Index SOI (right) in Summer (red line) and Winter (blue line). Errors bars are standard error.

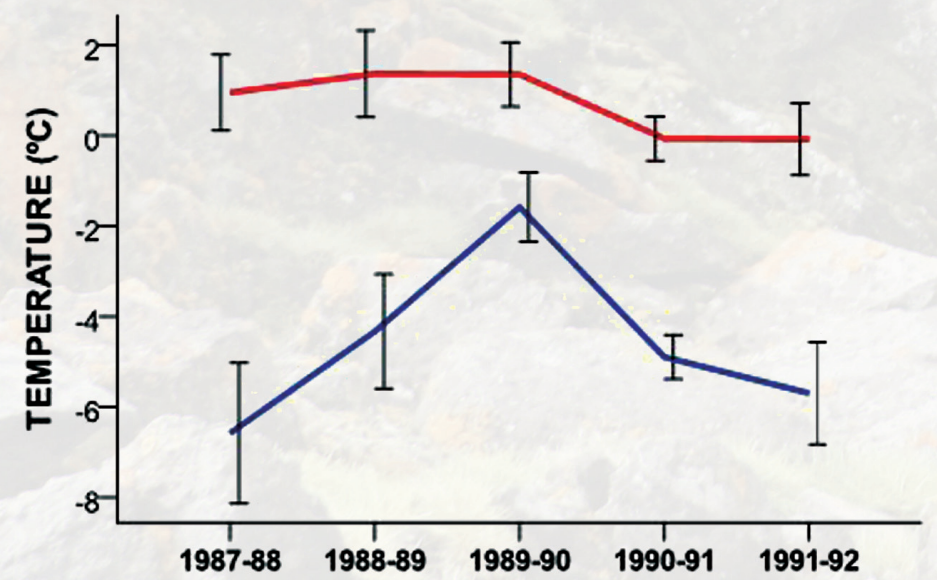

Figure 2. Year average temperature in Summer (red line) and Winter (blue line). Errors bars are standard error. 


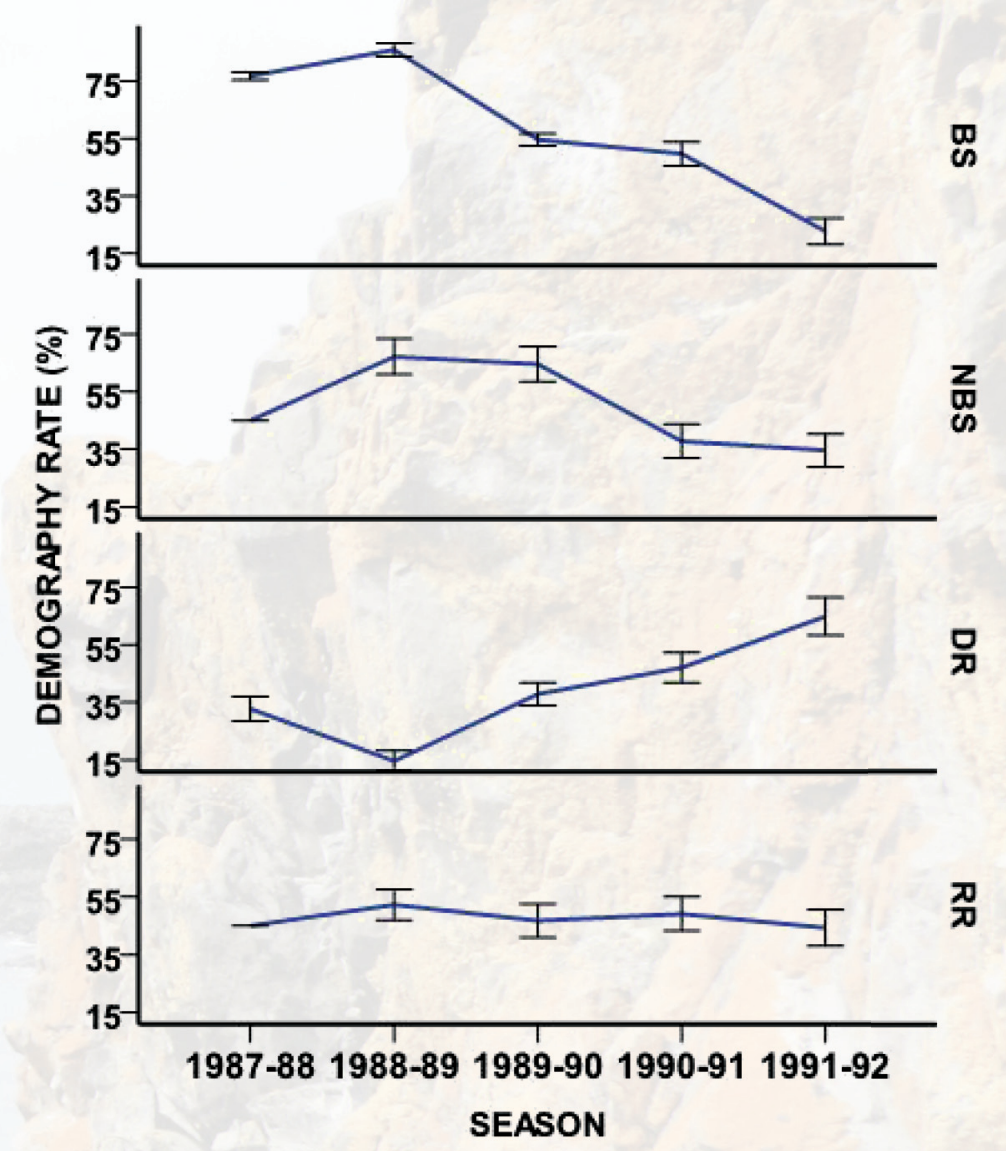

Figure 3. Average variation of breeder survival (BS), non-breeder survival (NBS), desertion rate (DR) and return rate (RR) in the breeding seasons. Error bars are standard error.

\section{Discussion}

Adults are less responsive to environmental variability nonetheless minimal variations on the survival causes pronounced decreases on the population growth rate (Barbraud et al., 2010). The standard trend in Stinker Point seems to be: higher temperatures in both summer and winter enhance survival and reduce desertion from breeding. Higher SOI and AOI mean higher temperatures in Antarctica (Gong \& Wang, 1999; Kwok \& Comiso, 2002). For breeders, the summer component must be the most important, since during breeding the energy expenditure to raise a chick overlaps with energy spent on survival. Other sub-Antarctic and temperate-water seabird's adult survival are affected by temperature and SOI (Croxall et al., 2002;
Rolland et al., 2010). As a consequence of the actual trend for Antarctic Peninsula region of warming, one can expect this population may not suffer declines caused by climate change. Such enhances can be considered probable, since the actual population numbers are greater than those from the studied years.

\section{Conclusion}

SGPs from Stinker Point are associated with warmer sea conditions. Their survival is probably enhanced by the current scenario of warming in the Antarctic Peninsula, as consequence no impending decrease caused by climate factors can be expected. 
Table 1. ANCOVA results of demography responses for climate variables by a Southern Giant Petrel population in Elephant Island.

\begin{tabular}{|c|c|c|c|c|c|c|}
\hline Dependent & Climate & Season & $\mathbf{F}$ & Slope & SE & $\mathbf{P}$ \\
\hline \multirow[t]{6}{*}{ BS } & SOI & Winter & 7.10 & -11.73 & 4.40 & 0.016 \\
\hline & & Summer & 10.70 & 12.36 & 3.78 & 0.005 \\
\hline & $\mathrm{AOI}$ & Winter & 2.85 & -17.83 & 10.56 & 0.110 \\
\hline & & Summer & 5.75 & 29.19 & 12.18 & 0.028 \\
\hline & $\mathrm{T}\left({ }^{\circ} \mathrm{C}\right)$ & Winter & 7.72 & 10.55 & 3.15 & 0.004 \\
\hline & & Summer & 9.36 & -6.45 & 8.18 & 0.441 \\
\hline \multirow[t]{6}{*}{ NBS } & SOI & Winter & 11.84 & 14.76 & 4.29 & 0.003 \\
\hline & & Summer & 0.87 & -3.42 & 3.68 & 0.365 \\
\hline & $\mathrm{AOI}$ & Winter & 2.29 & 17.16 & 11.33 & 0.148 \\
\hline & & Summer & 0.11 & 4.29 & 13.07 & 0.746 \\
\hline & $\mathrm{T}\left({ }^{\circ} \mathrm{C}\right)$ & Winter & 11.25 & 10.55 & 3.15 & 0.004 \\
\hline & & Summer & 0.62 & -6.45 & 8.18 & 0.441 \\
\hline \multirow[t]{6}{*}{ DR } & SOI & Winter & 0.31 & -2.67 & 4.82 & 0.587 \\
\hline & & Summer & 2.46 & -6.48 & 4.13 & 0.136 \\
\hline & $\mathrm{AOI}$ & Winter & 0.18 & -4.47 & 10.60 & 0.679 \\
\hline & & Summer & 3.10 & -21.53 & 12.22 & 0.096 \\
\hline & $\mathrm{T}\left({ }^{\circ} \mathrm{C}\right)$ & Winter & 0.18 & -1.41 & 3.34 & 0.678 \\
\hline & & Summer & 4.42 & -18.28 & 8.69 & 0.051 \\
\hline \multirow[t]{6}{*}{$\mathrm{RR}$} & SOI & Winter & 0.51 & 3.98 & 5.59 & 0.486 \\
\hline & & Summer & 0.07 & -1.28 & 4.80 & 0.792 \\
\hline & $\mathrm{AOI}$ & Winter & 2.21 & -16.71 & 11.23 & 0.155 \\
\hline & & Summer & 0.04 & -2.70 & 12.95 & 0.837 \\
\hline & $\mathrm{T}\left({ }^{\circ} \mathrm{C}\right)$ & Winter & 0.14 & 1.38 & 3.70 & 0.713 \\
\hline & & Summer & 3.06 & -16.79 & 9.61 & 0.099 \\
\hline
\end{tabular}

SOI: southern oscillation index; AOI: Antarctic oscillation index; BS: breeder survival; NBS: non-breeder survival; DR: desertion rate; RR: return rate; F: fisher's statistics; SE: standard error; P: significance probability.

\section{Acknowledgements}

This work integrates the National Institute of Science and Technology Antarctic Environmental Research (INCTAPA) that receives scientific and financial support from the National Council for Research and Development (CNPq process: $n^{\circ}$ 574018/2008-5) and Carlos Chagas
Research Support Foundation of the State of Rio de Janeiro (FAPERJ $n^{\circ}$ E-16/170.023/2008). The authors also acknowledge the support of the Brazilian Ministries of Science, Technology and Innovation (MCTI), of Environment (MMA) and Inter-Ministry Commission for Sea Resources (CIRM). 


\section{References}

Ainley, D.G.; Clarke, E.D.; Arrigo, K.; Fraser, W.R.; Kato, A.; Barton, K.J. \& Wilson, P.R. (2005). Decadal-scale changes in the climate and the biota of the Pacific sector of the Southern Ocean, 1950s to the 1990s. Antarctic Science, 17: 171-182.

Barbraud, C.; Rivalan, P.; Inchausti, P.; Nevoux, M.; Rolland, V. \& Weimerskirch, H. (2010). Contrasted demographic responses facing future climate change in Southern Ocean Seabirds. Journal of Animal Ecology, 80(1): 89-100.

Croxall, J.P.; Trathan, P.N. \& Murphy, E.J. (2002). Environmental change and Antarctic seabird populations. Science, 297: 1510-1514.

Gong, D. \& Wang, S. (1999). Definition of Antarctic Oscilation Index. Geophysical Research Letters, 26: 459-462.

Kwok, R. \& Comiso, J.C. (2002). Soutern Ocean Climate and Sea Ice Anomalies Associated with the Southern Oscillation. Journal of Climate, 15: 487-501.

Rolland, V.; Weimerskirch, H. \& Barbraud, C. (2010). Relative influence of fisheries and climate on the demography of four albatross species. Global Change Biology, 16: 1910-1922.

Sander, M.; Garcia, S.A.; Carneiro, A.P.B.; Cristofoli, S.I.; \& Polito, M.J. (2010). Band recoveries and juvenile dispersal of Southern Giant Petrels Macronectes giganteus marked as chicks in Antarctica by the Brazilian Antarctic Program (1984-1993). Marine Ornithology, 38: 119-124.

Warren, J.D.; Santora J.A. \& Demer, D.A. (2009). Submesoscale distribution of Antarctic krill and its avian and pinniped predators before and after a near gale. Marine Biology, 156: 479-491.

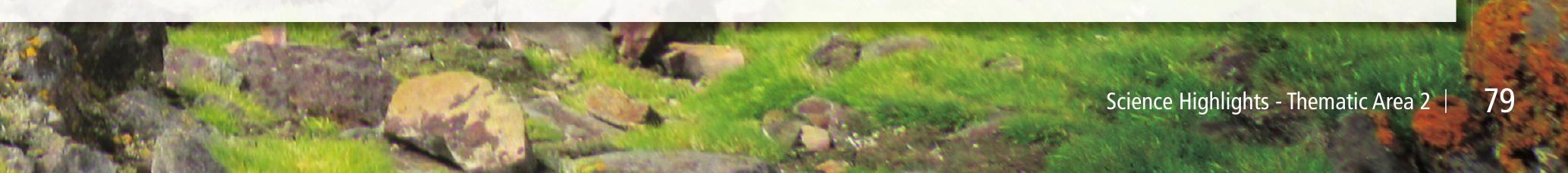

